\title{
Trayectoria, obra y cultura pedagógica de Antonio Ballesteros Usano
}

\author{
José Ignacio Cruz Orozco*
}

Antonio Ballesteros Usano fue un notable maestro que ejerció una brillante actividad durante más de medio siglo en España y México. En España como inspector de enseñanza y divulgador de la renovación educativa, y en suelo mexicano, a donde llegó en 1939 huyendo del franquismo, como escritor y formador de normalistas y pedagogos. Este trabajo reconstruye por primera vez su trayectoria de manera integral al aplicar la metodología histórico-educativa y emplear fuentes primarias inéditas. Aporta datos novedosos, corrige inexactitudes y analiza los referentes ideológicos y pedagógicos que orientaron su actuación. Entre las conclusiones destacan los fuertes vínculos que le unieron al movimiento de la Escuela Nueva, la eficacia profesional y la potente influencia que ejerció entre sus alumnos. Tan destacada trayectoria ha sido objeto de diversos reconocimientos en México, donde su memoria aún perdura cinco décadas después de su fallecimiento, lo que no ocurre en su tierra natal.

Antonio Ballesteros Usano was a remarkable teacher who exercised a brilliant career for more than half a century both in Spain and Mexico. In Spain he worked as a teaching inspector and disseminator of the educational renewal, and on Mexican soil, where he arrived in 1939 fleeing the Franco regime, he performed as a teacher for normal-school students and pedagogues, as well as a writer. This paper reconstructs his career in an integral way for the first time, by applying the historical-educational methodology and employing unpublished primary sources. It provides new data, corrects inaccuracies and analyzes the ideological and pedagogical references that guided his work. His strong links with the Progressive Education movement, his professional efficiency and the powerful influence that he exerted among his students are only some of the conclusions emphasized in the following research. It is worth noting that such an outstanding career has been awarded several recognitions in Mexico, where his memory still lasts even five decades after his death, which is not the case in his native Spain.
Palabras clave

Historia de la educación

Memoria histórica

Escuela Nueva

Trayectoria profesional

Formación de maestros

Exilio español

Keywords

History of education

Historical memory

Progressive education

Professional career

Teacher training

Spanish exile

Recibido: 18 de febrero de 2020 | Aceptado: 21 de septiembre de 2020

DOI: https://doi.org/10.22201/iisue.24486167e.2021.173.59755

* Profesor titular de la Universidad de Valencia (España). Doctor en Filosofía y Ciencias de la Educación. Líneas de investigación: política e historia de la educación española contemporánea; el exilio pedagógico de 1939. Publicaciones recientes: (2021), "Frente a la desamortización silenciosa. Estrategias de la enseñanza católica española", Educación XX1, vol. 24, núm. 2, pp. 399-420. DOI: https://doi.org/10.5944/educXX1.28271; (2019, en coautoría con S. García de Fez), "Cuando caiga Franco'. Las propuestas educativas para España desde el exilio (1945)", Historia y Memoria de la Educación, núm. 9, pp. 101-138. DOI: https://doi.org/10.5944/hme.9.2019.22879. CE: jose.i.cruz@uv.es 


\section{INTRODUCCIÓN Y METODOLOGÍA}

Antonio Ballesteros Usano fue un notable maestro y profesor cordobés que ejerció un intenso y brillante magisterio durante más de medio siglo. Primero en España como inspector y divulgador de la renovación educativa y, después, a partir de 1939 en México, país al que se vio forzado a exiliarse tras la finalización de la Guerra Civil. Allí llevó a cabo una fecunda tarea como formador del magisterio en la Escuela Normal Superior y en la Escuela Nacional de Maestros, entre otras instituciones. Falleció en 1974.

Su nombre resulta relativamente familiar a los especialistas y se han publicado trabajos sobre algunas de sus iniciativas (Cantón 1995, 1999; Farfán, 2004; Monter, 2011). El que aquí presentamos lleva a cabo por primera vez un estudio integral de su trayectoria tanto en España como en México. Aporta datos inéditos, corrige algunas inexactitudes y analiza los referentes ideológicos y pedagógicos que orientaron su actuación profesional y social, elemento éste de suma relevancia y sobre el que se realiza una lectura novedosa. Recupera la historia de uno de los maestros refugiados que llegó con una trayectoria profesional destacada, pero que dedicó sus años en México a la formación de maestros normalistas en instituciones mexicanas, aspecto este último muy singular y escasamente investigado.

Para confeccionarlo, se empleó la metodología histórico-educativa siguiendo el enfoque de la historia social de la educación (Viñao, 2008); y se tuvieron presentes las apreciaciones de Oropeza y García (2019) sobre su acercamiento al conocimiento de la gente común y su capacidad de interacción y negociación con el entorno. Al tratarse de un estudio biográfico, hemos tenido en cuenta las referencias, clásicas, de Dubet (1989) sobre identidad personal, vínculos con los procesos históricos y de socialización, compromisos para la acción y situaciones de cambio social y crisis; así como las aportaciones de Rutter (1996) sobre los momentos bisagra, especialmente significativos en las trayectorias personales al cerrar o abrir oportunidades y cambiar expectativas y creencias.

En lo que respecta a la categoría de cultura escolar seguimos la conceptualización del profesor Viñao, quien la concibe como:

...conjunto de teorías, ideas, principios, normas, pautas, rituales, inercias, hábitos y prácticas (formas de hacer y de pensar, mentalidades y comportamientos) sedimentadas a lo largo del tiempo en forma de tradiciones, regularidades y reglas de juego no puestas en entredicho, $y$ compartidas por sus actores, en el seno de las instituciones educativas (Viñao 2000: 73).

Se ha tenido muy presente el hincapié que realiza Julia (1995) sobre la vinculación de la cultura escolar con otras - religiosas, políticas, culturales, etc.- imperantes en el mismo momento histórico.

En cuanto a las fuentes documentales, se localizaron y consultaron datos y documentos de diversos archivos, bibliotecas y hemerotecas públicas españolas y mexicanas. Especial importancia tuvo el acceso a las fuentes primarias del Archivo General de la Administración (AGA) de Alcalá de Henares (España) y al que conservan los nietos del maestro Ballesteros en la Ciudad de México, muchas de ellas inéditas (Archivo de la Familia Ballesteros-Elías, en adelante AFBE). ${ }^{1}$ Lamentablemente, las vicisitudes del momento histórico que le tocó vivir a Antonio Ballesteros - la Guerra Civil, el exilio republicano de 1939 y la represión franquista- hicieron que numerosa documentación desapareciera.

También se recopilaron y analizaron los trabajos editados sobre el maestro Antonio Ballesteros y los textos que él redactó; y se

\footnotetext{
${ }^{1}$ Agradecemos a los familiares de Antonio Ballesteros y Emilia Elías las facilidades proporcionadas.
} 
recogieron testimonios de familiares, antiguos alumnos y compañeros, siguiendo la metodología de historia oral. Finalmente, se tuvieron en cuenta diversas fuentes secundarias - epistolarios, obras de referencia, textos compilatorios, monografías, etc.- en aquellas cuestiones que están bien documentadas, para suplir la ausencia de fuentes primarias y completar un abanico de referencias lo más contrastado posible. De especial interés ha sido el trabajo de Cruz y Civera (2017) sobre la maestra Emilia Elías, su compañera durante seis décadas.

Se buscó encuadrar la trayectoria de Antonio Ballesteros en las coyunturas sociales, culturales y políticas que le tocó vivir. A partir de sus diferentes facetas profesionales (inspector, divulgador pedagógico y profesor) se puso especial atención en analizar las corrientes ideológicas y las culturas pedagógicas que fundamentaron su actuación a lo largo de su intensa trayectoria. También se tomaron en cuenta los aspectos personales, familiares y psicológicos del personaje, con el objetivo de ofrecer un retrato lo más completo, consistente y contextualizado posible. Por último, al tratarse de una figura con una variada trayectoria profesional que abarcó casi seis décadas en dos países diferentes, la presente investigación se centra en aquellos elementos que consideramos más relevantes, lo que hace evidente la necesidad de profundizar las investigaciones sobre Antonio Ballesteros y otros maestros exiliados que trabajaron en instituciones educativas mexicanas.

\section{LOS AÑOS DE FORMACIÓN}

Antonio Ballesteros Usano nació el 11 de abril de 1895 en el número 5 de la calle de San Felipe de Córdoba. Su padre, Francisco Ballesteros Márquez, era maestro de primera enseñanza, natural de la localidad malagueña Carratraca.
Su madre, Encarnación Usano Alonso, era natural de la capital cordobesa. Entre esos dos territorios andaluces, Córdoba y Málaga, transcurrió la primera etapa de su vida y gran parte de su formación inicial, siguiendo los traslados profesionales paternos. ${ }^{2}$

En lo que respecta a los estudios, cursó la enseñanza primaria en la Escuela Graduada anexa a la Normal de Málaga y continuó la tradición y las posibilidades familiares al encaminar sus pasos hacia la docencia. Obtuvo el título de bachiller en el Instituto de Málaga en julio de 1909 y en septiembre del año siguiente se presentó al examen para conseguir el de maestro en la Escuela Normal de esa misma ciudad, el cual alcanzó con premio extraordinario. ${ }^{3}$

Una referencia destacada, que no se había puesto de manifiesto hasta ahora, es que Antonio Ballesteros no sólo siguió los pasos profesionales de su padre, sino que, más concretamente, recibió de éste una clara orientación hacia planteamientos innovadores en los que destacaba el interés por la mejora de la enseñanza, especialmente la pública, y su dimensión social. Francisco Ballesteros Márquez fue un reputado maestro cuyo influjo trascendió más allá de las aulas en las que impartió docencia. Escribió varios textos de orientación pedagógica (Ballesteros Márquez, 1888; 1899; 1906), divulgó esas ideas en ateneos y sociedades reformistas y ocupó la dirección de la Escuela Graduada de Málaga, un puesto de indudable relevancia dentro del escalafón del magisterio (Ballesteros Márquez, 1888; Viñao, 2003; Montero, 2008). No cabe la menor duda que la trayectoria de su padre marcó al joven Ballesteros, quien tiempo después, ya asentado en México, rememoró la figura paterna en términos comedidos, pero bien expresivos: “... es un profesor conocido. Ha escrito libros... ha dado conferencias... cuenta con una larga y noble vida de trabajo" (Ballesteros, 1963: s/p).

2 Archivo del Ministerio de Educación y Ciencia (en adelante, AGA), caja 1816-23, exp. personal de Antonio Ballesteros Usano.

3 AFBE. Certificado de notas expedido por la Escuela del Magisterio "Poeta Salvador Rueda" (Maestros) de Málaga, fechado el 25 de noviembre de 1950; AGA, caja 1816-23. 
Interesa resaltar que estas inquietudes encaminaron a nuestro personaje hacia un sector muy específico de la renovación educativa de su tiempo. Francisco Ballesteros tuvo destacados vínculos ideológicos y pedagógicos con la Institución Libre de Enseñanza (ILE). Más aún, mantuvo contacto directo con Francisco Giner de los Ríos, el alma de la institución, con quien sostuvo relaciones de amistad (Ballesteros, 1963). La ILE fue uno de los pilares más potentes, si no el que más, de la renovación educativa española desde su creación, en 1876, hasta el inicio de la guerra civil española en 1939, y es comúnmente reconocida por los especialistas como la máxima exponente del proyecto liberal en el ámbito de la educación en España (Moreno et al., 2013). El joven Ballesteros vivió en su círculo familiar, desde pequeño, los ideales de renovación, la preocupación por la mejora de la enseñanza y la necesidad de que el sistema educativo se orientara hacia el bienestar común.

Otro elemento que debe de tenerse muy en cuenta es que los datos que se conservan de su trayectoria profesional indican con mucha claridad que Antonio Ballesteros era un joven bien dotado intelectualmente, con una excelente metodología de trabajo y muy centrado en sus estudios. Todo ello le permitió dar un paso más allá dentro de lo que era habitual entre los jóvenes de su mismo origen social que estudiaban magisterio, al reproducir el modelo laboral paterno: lejos de quedarse en el primer peldaño dando clases en una escuela, tras conseguir el título de maestro, y dadas sus destacadas capacidades pedagógicas e intelectuales, fue uno de los poquísimos maestros que pudo optar por ingresar en la Escuela de Estudios Superiores del Magisterio, sita en Madrid.

Esa entidad constituía el vértice superior de la pirámide del sistema de primera enseñanza, según se denominaba a esa época a los estudios primarios, y recibió un potente influjo de la ILE. Se accedía a ella tras superar una prueba de acceso y allí se formaba durante tres cursos un pequeño grupo de los jóvenes maestros y maestras (la promoción de Antonio Ballesteros la componían 43 egresados) más prometedores y con los mejores expedientes, procedentes de toda España. Tras titularse, se convertían en los cuadros profesionales superiores del sistema público español de enseñanza primaria y eran destinados a ocupar los puntos de mayor responsabilidad y con mayor proyección: la dirección de las escuelas graduadas, la inspección de primera enseñanza y la docencia de las escuelas Normales (Molero y Pozo, 1989).

Precisamente, con ocasión de la presentación a los exámenes de ingreso a dicha Escuela los Ballesteros, padre e hijo, visitaron a Francisco Giner. El propio Antonio Ballesteros reconstruyó tal encuentro décadas después. El relato pone el acento en el interés que Giner manifestó por las actividades de su padre y por la situación del joven estudiante. Éste siempre le agradeció la acogida recibida que, según sus propias palabras, nunca olvidó (Ballesteros, 1963). Independientemente de los aspectos emotivos de esa situación, lo que nos señala tal episodio es que cuando Antonio Ballesteros llegó a Madrid ya conocía a la ILE y tenía relaciones significativas con algunas de sus figuras más destacadas. Interesa resaltar que su encuentro con las redes sociales, culturales y pedagógicas de la institución no se produjo al llegar a Madrid, sino previamente desde el núcleo malagueño de ella.

Como cabe suponer, el paso por la Escuela de Estudios Superiores del Magisterio resultó de suma trascendencia para el joven Ballesteros. Desde la perspectiva profesional, le permitió acceder a la formación de mayor especialización pedagógica que se impartía entonces en España y, posteriormente, ocupar puestos de responsabilidad en el sistema educativo. Pero también fue determinante en el ámbito más íntimo y personal: allí conoció a Emilia Elías Herrando, maestra madrileña y compañera de promoción (Civera y Cruz, 2017).

Resulta preciso indicar, para comprender con la mayor exactitud posible la dimensión 
personal y profesional de Antonio Ballesteros, que la pareja que formó con Emilia fue especialmente unida, tanto en lo familiar como en lo profesional. Una intensa sintonía y colaboración profesional rigió en todo momento su relación, que se reforzó aún más durante el exilio en tierras mexicanas. Al nombrar a Antonio Ballesteros no debemos olvidar que Emilia Elías siempre estuvo presente.

Antonio y Emilia finalizaron brillantemente los estudios en junio de 1914 y en ese momento sus caminos se separaron, aunque sólo momentáneamente. Emilia fue nombrada profesora de la Escuela Normal de Girona y Antonio marchó a ocupar una plaza de inspector de primera enseñanza en la ciudad de Jaén ${ }^{4}$ y estuvo destinado unos años en la inspección de Jaén y Cádiz. Finalmente, la pareja consiguió en 1917, tras haberlo intentado en repetidas ocasiones, coincidir en Segovia, ciudad próxima a Madrid, ella como profesora de la Normal y él en la inspección. Allí consiguieron la estabilidad que habían buscado durante años. Se casaron en Madrid en julio de 1918 y la familia se incrementó al poco con el nacimiento de Emilia en 1919, Encarnación en 1920 y Antonio en 1923.

\section{Ampliando HORIZONTES}

En el ámbito profesional, Antonio Ballesteros no se contentó con los estudios que había cursado a pesar de que suponían el máximo nivel existente en España en aquellos momentos en el ámbito pedagógico. Llevado por serias inquietudes intelectuales y profesionales buscó persistentemente ampliar sus conocimientos. Encontró respuesta en una de las iniciativas más destacadas que llevaba a cabo la Junta para la Ampliación de Estudios e Investigaciones Científicas (JAE), otra entidad directamente vinculada con la ILE, uno de cuyos objetivos consistía en promover la modernización de las estructuras educativas españolas por medio de la apertura a nuevos horizontes (Sánchez Ron, 1988; Canales, 2019).

La JAE desarrollaba un programa muy importante de becas e intercambios para que profesores e investigadores acudieran a universidades y centros de investigación extranjeros. Gracias a dicho programa, maestros (primaria), profesores (secundaria) e inspectores pudieron llevar a cabo provechosos viajes de estudio para conocer de primera mano las más interesantes experiencias pedagógicas de otros países europeos. Pero no sólo se trataba de ampliar conocimientos; ser becario de la JAE ("pensionado" era el término que se empleaba), suponía entrar en un selecto grupo caracterizado por alta exigencia laboral y reconocimiento profesional, además de adentrarse en los prestigiosos círculos de la Institución Libre de Enseñanza. En el caso concreto de Antonio Ballesteros significó intensificar aún más los vínculos que ya le unían a la entidad.

Nuestro personaje disfrutó de estas becas en varias ocasiones. La primera en 1921 -seguimos en este punto el trabajo de la profesora Marín (1991) - cuando formó parte del grupo de maestros e inspectores que realizó un viaje de estudios para conocer escuelas y entidades educativas renovadoras de Francia, Bélgica y Suiza. La siguiente oportunidad le llegó en el verano de 1924, cuando volvió a visitar centros de enseñanza franceses y belgas. Su interés fue incrementándose, de tal modo que volvió a solicitar una tercera beca, ésta individual, gracias a la cual pudo estudiar durante el curso 19251926 la formación profesional del magisterio de los países que había visitado el año anterior.

Estas experiencias fueron muy bien aprovechadas por el joven inspector Ballesteros y constituirían un amplio caudal de conocimientos y experiencias de gran utilidad durante toda su trayectoria profesional, como demuestra su producción escrita. No sólo contribuyeron sustancialmente a su formación, también incrementaron su reconocimiento en

${ }^{4}$ AGA, caja 1816-23, exp. personal de Antonio Ballesteros Usano. 
los grupos más inquietos del magisterio español. Una buena muestra de lo anterior es la valoración que José Castillejo, secretario de la JAE, realizó sobre nuestro personaje, cuando indicó en un informe fechado en octubre de 1926 que había cumplido "escrupulosamente sus deberes de pensionado" (Marín, 1991: 55). Escuetas palabras que dentro de los austeros códigos institucionales deben leerse como el pleno reconocimiento a un trabajo muy bien realizado.

Otro elemento que merece reseñarse es que Antonio Ballesteros participó en la Universidad Popular de Segovia durante los años en que residió allí. Su compromiso lo llevó a ser su secretario entre 1921 y 1932. Se trataba de una interesante iniciativa de promoción y divulgación cultural y educativa, muy en la línea de las inquietudes de la ILE. La Universidad Popular, entre otras actividades, desarrolló un intenso programa de conferencias y organizó una biblioteca circulante (GarcíaVelasco et al., 2017; Valles et al., 2019).

Dentro del panorama de iniciativas similares que se dio en España en aquellos años, la experiencia de la Universidad Popular segoviana destacó por su solidez. Consiguió tener sede propia mediante la compra y rehabilitación de la capilla de San Quirce, un importante edificio histórico en el casco histórico de la ciudad (por cierto, mediante un préstamo bancario del que uno de los avales fue el propio Ballesteros). Creada en 1919 por el poeta Antonio Machado, destinado entonces como profesor de francés en el instituto de la ciudad, la Universidad ha continuado, con altibajos, sus actividades hasta la actualidad, ahora con el nombre de Real Academia de Historia y Arte de San Quirce (Valles et al., 2019).

Para cumplir eficazmente sus funciones de secretario, Ballesteros recurrió a sus amigos y conocidos de la ILE, en especial a Alberto Jiménez Frau, director de la Residencia de Estudiantes, quien le ayudó permanentemente facilitándole contactos y hablando para que expertos y especialistas, casi todos próximos a la ILE, acudieran a la ciudad castellana a impartir conferencias. La relación fue tan intensa que la Universidad llegó a tener una cuenta abierta en la propia contabilidad de la Residencia (García Velasco et al., 2017).

\section{Divulgador de la Escuela Nueva}

Cualquier estudio sobre Antonio Ballesteros debe incluir un ámbito más a los que ya hemos ido señalando hasta ahora. También fue un destacado publicista y divulgador educativo. Su primer texto educativo Características de la enseñanza primara en Francia, Bélgica y Cantón Suiza en Neuchatel (Ballesteros, 1924) fue editado por la JAE y estaba directamente relacionado con los viajes de estudio. Redactó bastantes más; de las experiencias foráneas le interesó especialmente la metodología de los centros de interés ensayada por Ovidio Decroly en Bélgica, a quien conoció y con el que mantuvo una intensa relación profesional. Fruto de esas experiencias publicó El método Decroly (Ballesteros, 1928a).

En este capítulo de su vida debe calibrarse en su justa medida todo lo que supuso la vinculación con la Revista de Pedagogía en las décadas de 1920 y 1930. Esta publicación se editó en Madrid desde 1922 hasta 1936 bajo la dirección de Lorenzo Luzuriaga, otro egresado de la Escuela de Estudios Superiores del Magisterio y figura muy destacada del sector progresista de la enseñanza (Barreiros, 1984; 1989). Se trata de un destacado e interesante proyecto pedagógico, claramente decantado en pro de la renovación pedagógica, con potentes vínculos con el movimiento internacional de la Escuela Nueva (la Revista de Pedagogía fue su portavoz en España); estaba basado en planteamientos académicos rigurosos, a la par que hizo gala de una profunda voluntad divulgadora (Viñao, 1994-1995).

La colaboración de Antonio Ballesteros en esa publicación resultó intensa. En sus páginas aparecieron numerosos artículos con su firma, de modo que los recuentos bibliométricos lo sitúan en el tercer lugar en número 
de colaboraciones (Viñao, 1994-1995: 16). Además, también publicó en el sello editorial de la revista la mayor parte de sus libros. Ya hemos citado El método Decroly y la nómina debe ampliarse con: Distribución del tiempo y del trabajo (Ballesteros, 1924); La escuela graduada (Ballesteros, 1926), La cooperación en la escuela (Ballesteros, 1928b), Las escuelas nuevas francesas y belgas (Ballesteros, 1930), Organización escolar (Ballesteros y Sáinz, 1934) y La preparación del trabajo en clase (Ballesteros, 1935).

Este aspecto concreto, clave a nuestro juicio para definir la cultura pedagógica de Antonio Ballesteros, resulta evidente por los trabajos y publicaciones que se ubicaron dentro de las aportaciones reformistas de la Escuela Nueva. Su tarea consistió, básicamente, en dar a conocer las experiencias novedosas que fue conociendo gracias a las becas, las relaciones que estableció y las lecturas que llevó a cabo. Ahora bien, debe tenerse en cuenta que, como señala acertadamente la profesora Del Pozo (2003-2004), los divulgadores de la Escuela Nueva en España copiaron, glosaron, tradujeron y calcaron los planteamientos diseñados por los pedagogos extranjeros, pero salvo contadas excepciones, entre las que no se encuentra nuestro personaje, no realizaron ninguna síntesis ni aportación novedosa. Se trató de un modelo de difusión presidido por las iniciativas individuales.

\section{Segunda República}

Teniendo en cuenta lo señalado hasta el momento, no puede extrañarnos que Antonio Ballesteros estuviera destinado a jugar un papel destacado en la política educativa puesta en marcha por los gobiernos del primer bienio de la Segunda República, los cuales se apoyaban en la coalición parlamentaria republicano-socialista. Tras haber desempeñado con suma competencia sus tareas profesionales, ser un destacado especialista y encontrarse ubicado en los círculos más avanzados de la renovación pedagógica, resultaba evidente que, con el cambio de régimen, estaba destinado a ocupar un lugar en el núcleo director de la política educativa.

Al respecto, el Ministerio de Instrucción Pública puso en marcha casi de inmediato una serie de importantes medidas destinadas a potenciar las instituciones educativas públicas, actualizar y modernizar las prácticas en las aulas e impulsar diversas medidas para alejar la presencia confesional. Para llevarlas a cabo se organizaron algunos organismos de carácter técnico, encabezados por funcionarios en plena sintonía con el programa republicano. Una de esas entidades fue la Inspección Central de Primera Enseñanza, organizada a partir de un decreto datado el 2 de diciembre de 1932, la cual se convirtió en un auténtico núcleo dinamizador e impulsor de las medidas reformistas gubernamentales. Algunas de sus tareas consistieron en planificar y diseñar los instrumentos, mecanismos y herramientas para hacer llegar a todas las aulas distribuidas a lo largo y ancho del país las disposiciones dictadas desde el ministerio de la manera más eficaz posible (Jiménez, 1984; López, 2013).

Entre los técnicos que se encargaron de ponerla en marcha se encontraba Antonio Ballesteros, quien tuvo especial protagonismo ya que, según los especialistas, él fue responsable de la redacción del decreto fundacional (Castán, 2017). Como se indicó, la Inspección Central desempeñó un papel esencial en la centralización y movilización de las iniciativas en política educativa; pero, independientemente de ese sesgo más ideológico, la entidad y los inspectores que la integraban destacaron por su buen hacer técnico-pedagógico. Un buen ejemplo de ello es que el citado decreto estuvo vigente hasta 1967, durante tres décadas y media, la mayor parte en pleno franquismo (Jiménez, 1984). Se trató sin duda de uno de los momentos bisagra, comentados con anterioridad. Este paso de indudable significación política marcó su trayectoria personal y profesional, y debe subrayarse que en las nuevas responsabilidades volvió a destacar por su competencia profesional. 
Ya hemos señalado en las páginas precedentes los compromisos pedagógico, profesional y personal del inspector Ballesteros, mismos que se incrementaron con la militancia en la década de 1930. Se encuentra perfectamente documentado (seguimos en este punto el trabajo de De Luis [2002], aunque falte concretar algunos aspectos), que durante los años de la República militó en la Federación de Trabajadores de la Enseñanza (FETE), organización integrada en el sindicato socialista Unión General de Trabajadores (UGT). Durante esos años, y en consonancia con el proceso de radicalización que se dio en las sociedades europeas y española, se produjo un acercamiento entre algunos sectores socialistas y comunistas, producto de lo cual se produjo un trasvase de los primeros a las filas del Partido Comunista de España (PCE) ${ }^{5}$

Esa fue la trayectoria seguida por Antonio Ballesteros, quien acabó militando en el PCE durante el periodo de la II República, sin que hasta el momento se pueda precisar la fecha concreta de su afiliación. Este hecho subraya la transcendencia de las decisiones tomadas en esas fechas. Su militancia comunista resulta incuestionable, y aunque no llegó a ocupar puestos de primera fila, siempre fue considerado un cuadro solvente.

$\mathrm{Al}$ respecto cabe señalar que, al igual que tantos otros momentos de su vida, Ballesteros no transitó por esos caminos en solitario, sino que estuvo acompañado por su esposa Emilia Elías, cuya militancia, en consonancia con su vehemente carácter, tuvo bastante mayor relevancia que la de Antonio. Entre otros aspectos, fue nombrada miembro del Comité Central del PCE en 1933, ocupó puestos de dirección en la Agrupación de Mujeres Antifascistas (AMA) - una entidad de confluencia de las fuerzas de izquierda que acabó controlada por las comunistas-, y durante bastante tiempo fue una persona muy cercana a la dirigente Dolores Ibárruri, Pasionaria. Por ello sería más correcto apuntar que fue Antonio Ballesteros quien acompañó a su esposa, $y$ no al revés (Civera y Cruz, 2017).

Como resulta bien conocido, en julio de 1936 parte del ejército español, apoyado por sectores derechistas, se sublevó contra el gobierno legítimo de la República y comenzó la Guerra Civil. Las primeras semanas fueron críticas para el bando gubernamental, que perdió mucho terreno, hasta que en noviembre el frente se estabilizó tras los fuertes combates de la batalla de Madrid. En esas fechas, Antonio Ballesteros continuó prestando sus servicios al gobierno legítimo y a la causa republicana, desempeñando labores de dirección y organización en la Inspección Central (Andrés et al., 1937). Sin embargo, como la situación resultaba crítica en muchos aspectos, también tuvo que asumir nuevas responsabilidades, como la organización de los mecanismos para ayudar a los niños y niñas afectados por la proximidad de los frentes de batalla, por medio de la puesta en marcha de las estructuras situadas bajo el rótulo de "infancia evacuada" (De Luis, 2002; Cruz, 2018).

Debe tenerse en cuenta que las fuertes tensiones sociales y políticas que presidieron la vida española durante la República explotaron con el estallido bélico. Dentro de ese complejo panorama, las propuestas reformistas situadas dentro de la legalidad vigente de una entidad de raigambre burguesa como la ILE no fueron bien vistas por grupos libertarios y marxistas que abanderaban discursos e iniciativas radicales, en un contexto de confrontación armada y con una retaguardia en donde en muchos lugares las milicias populares aplicaban violentamente su modelo revolucionario. Se produjo lo que algunos especialistas conceptualizan como una suma de enfrentamientos. Como consecuencia de uno de ellos, la lucha de clases, buen número de los miembros de la

\footnotetext{
5 En el Archivo Histórico del PCE, actualmente custodiado en la Biblioteca Histórica de la Universidad Complutense de Madrid, no se conservan ficheros ni relaciones de afiliados. Las referencias a la militancia de Antonio Ballesteros se basan en las fuentes secundarias citadas y en informaciones orales de familiares y amigos.
} 
ILE que se desempeñaban en el gobierno tuvieron que buscar protección - pese a ser fieles republicanos- y muchos acabaron saliendo de España a la primera oportunidad que se les presentó (Pérez, 2006; Valender, 2017).

Antonio Ballesteros y Emilia Elías, que mantenían intensos vínculos profesionales y personales con la ILE y sus integrantes, en esos momentos se orientaron en completa sintonía con la militancia comunista. Secundaron por completo la política antifascista del PCE y apoyaron las iniciativas del gobierno republicano, en el cual la cartera de educación estaba ocupada por el dirigente comunista Jesús Hernández (Ballesteros, 1937; Cruz, 2018). Ello los alejó, profesional, política y personalmente, del devenir de la institución y de gran parte de sus miembros, quienes rechazaban las ideologías totalitarias y no estaban de acuerdo con algunas actuaciones revolucionarias puestas en práctica tras la sublevación, en consonancia con su origen social, burgués, e ideológico, liberal (Valender, 2017). En consecuencia, como les ocurrió a tantos españoles y españolas en esas cruciales fechas, la adscripción ideológica marcó significativos alejamientos.

El matrimonio Ballesteros Elías y sus dos hijas, Emilia y Encarnación, se vieron obligados a abandonar España en febrero de 1939 a causa del avance de las tropas franquistas sobre Cataluña. Al ser los padres destacados funcionarios, la familia había seguido el periplo del gobierno republicano: al pasar de Madrid a Valencia en noviembre de 1936, y un año después de Valencia a Barcelona, se sumaron a las oleadas de refugiados que huyeron camino de Francia en esas trágicas semanas. Pero la familia no estaba completa; faltaba Antonio, el hijo menor, que había abandonado España antes, en una de las expediciones de niños evacuados a la URSS que supervisaba su padre (Zafra et al., 1989). Los Ballesteros cruzaron la frontera y comenzaron una nueva etapa en sus vidas, la del exilio, y como tantos otros compatriotas, debieron realizar cambios drásticos y forzadas adaptaciones.

Al respecto se debe tener en cuenta, a modo de balance, que Antonio Ballesteros contaba en esos momentos con una formación muy sólida, completa y actualizada, basada en la cultura pedagógica progresista del movimiento de la Escuela Nueva. En ella había dejado una huella profunda el ideario de la ILE, pero también se constata su preocupación e interés por la dimensión social de la educación que presentaba la Escuela Nueva, cuyos principios ayudó a difundir intensamente por medio de sus numerosos escritos. Precisamente fue esa inquietud social, junto con su amplio conocimiento de la escuela primaria y su convicción en la necesidad de un progreso social lo que le llevó a la militancia, socialista primero, comunista después. Tenía, por tanto, dos amplios universos ideológicos de referencia, más político uno, más pedagógico el otro.

\section{EL EXILIO}

La familia Ballesteros-Elías pudo eludir con rapidez los campos de refugiados y pasaron en París las primeras semanas de mayo de 1939. Abandonaron definitivamente suelo francés a finales de ese mes en el Sinaia, el primero de los fletes colectivos, y quizá por ello el más simbólico, organizado por los organismos de ayuda de los republicanos españoles. El destino del buque era el puerto mexicano de Veracruz, y durante la travesía, e iniciando una pauta que siguieron otras expediciones, se imprimió: Sinaia. Diario de la primera expedición de republicanos españoles a México. El periódico, de modesta confección, pero de gran interés, tuvo como director a Juan Rejano, cordobés como Ballesteros, el cual, según su propia confesión, contó con la "colaboración de un animoso grupo de maestros de primaria" entre los que se encontraba nuestro personaje (“Colofón”, 1939: 21; Pla, 2003). ${ }^{6}$

${ }^{6}$ Hemos empleado la reproducción facsímil de Sinaia. Diario de la primera expedición de republicanos españoles a México realizada en 1989. Todas las citas que realizamos del mismo están tomadas de dicha reproducción. 
En las páginas de Sinaia encontramos referencias a las actividades de Antonio Ballesteros y Emilia Elías durante los días de navegación. Dada la presencia de un buen número de niños en el pasaje, y las profundas inquietudes pedagógicas de la pareja, improvisaron unas aulas para que aquéllos aprovecharan el tiempo lo mejor posible. Pese a que se trataba de una estructura provisional con pocos días de vigencia, lideraron un grupo de maestros y maestras, llevaron a cabo una evaluación inicial de cada uno de los alumnos, organizaron cuatro niveles diferenciados de docencia y, posteriormente, trabajaron diariamente con ellos siguiendo el sistema de centros de interés de Decroly (“Los peques", 1939: 1).

Ballesteros realizó también otra colaboración en esa publicación que merece reseñarse. En el último número, fechado el día de llegada, apareció el artículo "La escuela popular mexicana”, en el cual describe algunas de las principales características de la política educativa del presidente Cárdenas (Ballesteros, 1939; Cantón, 1999). El texto finaliza con una expresiva llamada sobre los pasos que debían seguir los exiliados españoles - que en buena lógica nos indica también el propósito del autor- a la hora de comenzar su camino en la sociedad que los iba a acoger:

$\mathrm{Al}$ incorporarnos al trabajo activo en México no debemos olvidar que por nuestra condición antifascista, por lealtad hacia el pueblo de México y a su Presidente Cárdenas... Por deber patriótico de apresurar la reconquista de España, hemos de convertirnos en activos colaboradores de esta obra magnífica... (Ballesteros, 1939: 20).

Tras insistir en la necesidad de colaborar activamente con el cardenismo, concluía que tanto mexicanos como españoles tenían que aunar esfuerzos para combatir al enemigo común: el fascismo.

El buque atracó en Veracruz el 13 de junio de 1939 y la mayor parte de los exiliados se trasladó al poco tiempo a la capital mexicana. La principal preocupación de todos ellos, como la de cualquier emigrante recién llegado, fue comenzar a situarse en la sociedad de acogida, especialmente en buscar el modo de ganarse la vida. Antonio Ballesteros y Emilia Elías fueron de los primeros en conseguir un puesto de trabajo, ya que a las pocas semanas de su llegada comenzaron a impartir clases en centros de formación dependientes del gobierno mexicano. Esa sería la ocupación de ambos durante más de dos décadas, hasta su jubilación a finales de la década de los años sesenta.

La pareja siguió en esa nueva etapa un itinerario escasamente transitado entre los integrantes del exilio pedagógico de 1939. Trabajaron plenamente insertados en la sociedad mexicana. Fueron profesores en instituciones públicas dependientes de la administración de ese país, formaron siempre a alumnado mexicano y tuvieron como compañeros a profesorado mexicano, salvo contadas excepciones. Fue una opción sensiblemente diferente a la mayoría de sus colegas exiliados, que en buen número se integraron en los centros educativos creados por los republicanos, los denominados colegios del exilio (Cruz, $2005 ; 2011)$. Fue una decisión forzada por las circunstancias, pero que los singularizó dentro del exilio republicano español y que debe destacarse por lo que supuso de interacción e intercambio con la sociedad mexicana en general y los sectores educativos, en particular.

Afrontaron esa nueva etapa en un momento delicado de su vida. Ballesteros contaba con 44 años en aquellas fechas $y$, aunque animoso y con buena salud, había sobrepasado la juventud y debía hacer frente a responsabilidades familiares. En este nuevo momento bisagra ellos volvían a contar a su favor con elementos de gran utilidad para superar la ruptura, la derrota, el tránsito y su inserción en la sociedad de acogida: una sólida formación, brillante hoja de servicio, inmejorable metodología de trabajo y firme voluntad de reconstruir sus itinerarios profesionales. A todo 
ello se debe sumar que disponían de algunos contactos previamente establecidos con destacados profesores mexicanos, como Ismael Rodríguez, por su labor profesional, sindical y política en reuniones y congresos vinculados al movimiento de la Escuela Nueva (Cantón, 1995; Reyes, 1982).

Todo ello permitió a Antonio Ballesteros continuar en el exilio mexicano su trayectoria profesional en la enseñanza, aunque hubo de modificar el perfil particular de su intervención: de la supervisión y la planificación típicas de la inspección, a la intervención docente en las aulas con el alumnado de magisterio. A partir de julio de 1939 nuestro protagonista y su esposa comenzaron a impartir clases en la Escuela Normal Superior - de la cual era director el citado Ismael Rodríguez-y, desde septiembre de ese mismo año, en la Escuela Nacional de Maestros. Se trataba de las instituciones de formación de profesores más importantes del país, ubicadas en la Ciudad de México (Monter, 2011). Además, completaban su actividad laboral dando clases en la Escuela Normal de Pachuca, en la capital del estado de Hidalgo, donde colaboraron durante más de dos décadas. Su opción por integrarse en la sociedad que les acogió fue firme y sincera; buena muestra de ello es que se naturalizaron mexicanos en septiembre de 1940, apenas un año después de su llegada.

Como ya quedó señalado, la pareja formada por Antonio Ballesteros y Emilia Elías estuvo intensamente unida. Desde que se conocieron en la Escuela de Estudios Superiores del Magisterio de Madrid en 1911 compartieron similares intereses profesionales, culturales, sociales y políticos. Su trayectoria en España fue muy parecida, aunque los perfiles laborales específicos presentaran diferencias. Los múltiples lazos que los vinculaban se incrementaron aún más en tierras mexicanas, en donde, además de compartir los espacios familiar, social y político, comenzaron a trabajar juntos, ya que formaban parte de los claustros de las mismas entidades de enseñanza y trabajaban e impartían la docencia al mismo alumnado.

En lo que respecta al ámbito familiar, se establecieron en un modesto apartamento en la calle Abraham González 14, en la zona central de la capital muy próxima a la Glorieta de Colón. Allí vivieron toda la vida junto a sus hijas Emilia y Encarnación, quienes se formaron y trabajaron como profesionistas en la Ciudad de México. El menor, Antonio, que había sido evacuado a la Unión Soviética durante la Guerra Civil, se estableció definitivamente en Moscú con la finalización de la guerra mundial. La familia, pese a la distancia, barreras y obstáculos de todo tipo, se mantuvo en contacto, aunque sólo volvió a reunirse temporalmente en un par de ocasiones en la segunda mitad de la década de 1960, cuando Antonio pudo viajar a México y visitar a sus padres y hermanas. ${ }^{8}$

Como ya se indicó, Antonio Ballesteros fue profesor en la Escuela Normal Superior, donde se formaban profesores de educación secundaria, y en la Escuela Nacional de Maestros. Debe señalarse que, aunque esa opción fue escasamente transitada entre los docentes exiliados, no estuvo solo; también trabajaron en ellas durante diversos periodos los profesores republicanos españoles Luis Castillo Iglesias, Laureano Poza Juncal, Ana María Palazón, Jesús Bernárdez Gómez y Carlos Sáenz de la Calzada, entre otros. ${ }^{9}$ En la ciudad de Pachuca contaron con el apoyo y la compañía de la psicóloga Regina Lagos, también exilia$\mathrm{da}$, a la que les unió una entrañable amistad. La pareja viajó en autobús a la capital del estado de Hidalgo una o dos veces por semana

\footnotetext{
AFBE. Certificado de nacionalización de Antonio Ballesteros Usano, expedido por la Secretaría de Relaciones Exteriores con fecha 10 de septiembre de 1940.

${ }^{8}$ Conversaciones con los nietos del Antonio Ballesteros celebradas el 18 de octubre de 2019 en la Ciudad de México.

${ }^{9}$ Casi todos, por no decir todos, a la espera de investigaciones que ponga negro sobre blanco esta interesante página del exilio pedagógico español de 1939, que se caracterizó por la intensa inmersión profesional en instituciones docentes mexicanas.
} 
durante más de 20 años (Monter, 2011; Civera y Cruz, 2017). ${ }^{10}$

Antonio Ballesteros se vio favorecido en gran medida por los cambios en la coyuntura política mexicana. Desde finales de 1940, con el inicio de la presidencia del general Manuel Ávila Camacho, se produjeron sensibles modificaciones: se establecieron como objetivos principales de la acción gubernamental la modernización e industrialización del país, y en lo que respecta al ámbito de la enseñanza también se modificaron las prioridades. Dentro de ese proceso de reorientación se impulsó la unidad nacional y la democratización política, lo que significó, en gran medida, un alejamiento de los postulados revolucionarios de la educación socialista (Civera, 2011).

Dentro de ese cambio de coyuntura, Antonio Ballesteros, conocido por todos en su etapa mexicana como el maestro Ballesteros, pudo abrirse paso y consolidar un serio prestigio como docente gracias a su buen hacer; a las instituciones en las que trabajó aportó intervenciones competentes, modernas y actualizadas, y a ello se sumó la seriedad en el puntual desempeño de todas y cada una de las tareas que se le encomendaron (Farfán, 2004).

Pero no finalizó aquí su actividad profesional, ya que subió un peldaño más en su carrera profesional: en febrero de 1959 fue nombrado profesor del Colegio de Pedagogía de la Facultad de Filosofía y Letras de la UNAM, concretamente en la cátedra de Teoría de los sistemas de educación secundaria (Becerra, 1994). Este último encargo debe ser considerado como un sentido reconocimiento, ya que supuso el ascenso al estamento universitario, precisamente en la UNAM, la casa de estudios más prestigiosa del país (Becerra, 1994). ${ }^{11}$ Antonio Ballesteros y Emilia Elías se jubilaron de la Escuela Nacional de Maestros en febrero de 1968. Unos años antes, en 1965, él había hecho lo propio en la UNAM.

\section{LIBROS, REVISTAS Y MILITANCIA}

Como ya se apuntó, Antonio Ballesteros desarrolló en España una destacada labor como escritor y divulgador pedagógico, faceta que no olvidó en México. La primera iniciativa al poco de llegar fue la dirección, junto a su compañero Juan Comas, de la revista Educación y Cultura, editada en la Ciudad de México durante 1940; salieron 12 números. Se trata de una propuesta sólida y de mirada amplia, que seguía los pasos de la española Revista de Pedagogía. Aunque no prosperó, cumplió como carta de presentación ante los círculos educativos progresistas mexicanos, y posibilitó establecer e intensificar contactos con destacados profesores como Ismael Rodríguez, José Mansidor y Francisco Larroyo (Cantón, 1995).

Posteriormente, Ballesteros publicó varios textos pedagógicos y manuales de las asignaturas que impartía, aprovechando la demanda de ese tipo de obras por parte de maestros en ejercicio o del alumnado normalista. El primero del que tenemos constancia fue Cómo se organiza la cooperación en la escuela primaria (Ballesteros, 1940), al cual siguió Organización de la escuela primaria (Ballesteros, 1943). Casi una década después apareció Organización escolar (Ballesteros y Sáinz, 1952), reedición del texto que había publicado en 1935. En esa ocasión formó parte del catálogo de la Editorial Losada de Buenos Aires bajo la tutela de Lorenzo Luzuriaga, evidencia clara de que la red de la Revista de Pedagogía pervivió en el exilio.

\footnotetext{
${ }^{10}$ Entrevista con las maestras Lucila Pérez, Carolina Bocardo, Amalia González y el maestro Javier Hernández en el domicilio de este último en la ciudad de Pachuca, realizada por José Ignacio Cruz el 24 de abril de 2004.

11 AFBE. Algunas referencias, antiguas y recientes, indican que Antonio Ballesteros obtuvo el doctorado en Pedagogía por la Sorbona. Ver, a modo de ejemplo, el Portal de los Archivos Españoles (PARES), en: http://pares. mcu.es/ParesBusquedas20/catalogo/autoridad/124004 (consulta: 24 de octubre de 2019). Al respecto debemos afirmar que a lo largo de esta investigación no encontramos ningún documento que lo acredite. Es más, en los curriculae autógrafos que se custodian en el archivo familiar no existe ninguna mención sobre ese particular. Quizá su trabajo en la UNAM pudiera dar pie a éste, casi con toda seguridad, equívoco.
} 
La siguiente obra fue un libro de texto, $\mathrm{Ci}$ vismo para primer año de secundaria (Elías y Ballesteros, 1955) en colaboración con Emilia, al que siguió, ya en solitario, La adolescencia: ensayo de una caracterización de esta edad (Ballesteros, 1965), temática que volvió a tratar en La educación de los adolescentes (Elías y Ballesteros, 1969), nuevamente junto a su esposa. También volvió a publicar junto con Sáinz y Luzuriaga, entre otros, en Métodos de la nueva educación (Luzuriaga et al., 1961). Las publicaciones de la etapa del exilio muestran una clara deuda con la producción realizada en España. Ballesteros llegó a México con una carrera profesional y pedagógica bien desarrollada, y a partir de la década de 1940 se centró básicamente en trasmitir sus conocimientos, tras adaptarlos a la realidad normalista de México.

Muchas de estas publicaciones han disfrutado de una larga vida con numerosas reediciones. Organización de la escuela primaria (Ballesteros, 1943) llegó, en 1983, a la $14^{\circ}$ edición, cuatro décadas después de la primera. Igualmente, han gozado de gran éxito los textos sobre la adolescencia, una temática en parte novedosa que constituyó el interés central de Ballesteros en la década de 1960 . Del volumen La adolescencia: ensayo de una caracterización de esta edad (Ballesteros, 1965) se publicó la $17^{\circ}$ edición en 1985 y de La educación de los adolescentes (Elías y Ballesteros, 1969), la sexta en 1983. No era la primera vez que sus textos tenían éxito; varios de los editados en España también contaron con algunas reediciones, pero no alcanzaron, ni de lejos, las importantes ventas mencionadas.

Debe tenerse en cuenta que Emilia Elías y Antonio Ballesteros se dedicaron a la redacción de libros guiados no sólo por motivos estrictamente profesionales, sino, en cierta medida, forzados por las circunstancias. Aunque en todo momento cumplieron estrictamente sus compromisos laborales y gozaron de un amplio reconocimiento allí donde trabajaron, siempre tuvieron contratos eventuales por horas, por lo que la edición de textos fue un modo de completar los ingresos familiares (Civera y Cruz, 2017).

En lo que respecta a sus actividades políticas, Antonio Ballesteros continuó militando en la FETE y en el Partido Comunista de España. En México, siguiendo a De Luis (2009), continuó alineado con el sector comunista del sindicato Unión General de Trabajadores (UGT) liderado por César García Lombardía, Domingo Amo y Ramón Ramírez. El grupo fue mayoritario hasta finales de la década de 1940, en que se impuso otro netamente socialista vinculado a los dirigentes Indalecio Prieto y Rodolfo Llopis.

Ballesteros fue secretario general de la directiva de la delegación mexicana de la UGT desde 1946 hasta 1948. Precisamente en los momentos de mayor debilidad, y cuando la influencia comunista declinaba, para entrar en franca decadencia poco después. A partir de su elección, la hegemonía entre los socialistas españoles en México se decantó hacia el sector dirigido desde Toulouse (Francia) por Rodolfo Llopis - por cierto, otro egresado de la Escuela de Estudios Superiores del Magisterio-el cual rechazaba cualquier contacto con los comunistas.

Dentro de este tan enrarecido ambiente, nuestro personaje siguió vinculado al PCE, ya que participaba activamente en las reuniones de su agrupación hasta finales de la década de 1950. En los documentos que se custodian en el archivo familiar se encuentran materiales de trabajo político (notas de reuniones, informes, folletos y escritos del Partido Comunista de España y del Partido Comunista de la Unión Soviética) profusamente subrayados y anotados. ${ }^{12}$ Un estudio reciente sitúa a Ballesteros entre los sectores más abiertos, aglutinados en torno a la revista del PCE Nuestro Tiempo -en la cual colaboró- y a su director, Juan Rejano,

12 AFBE. Algunos de los títulos que se conservan son: Problemas económicos del socialismo en la URSS, y XIX Congreso del Partido de los Comunistas de la URSS. 
quien también había sido director del diario del Sinaia y con el que Ballesteros siempre mantuvo fuertes lazos de amistad (Ballesteros, 1953). Cabe mencionar que en esta etapa la militancia de Emilia Elías tuvo bastante mayor proyección que la de su marido (Reyes, 1982; Aznar, 2019).

Más adelante, también según fuentes de la familia Ballesteros-Elías, documentos del archivo familiar dan cuenta de los reparos de la pareja a participar en algunos actos del PCE, y de su distancia respecto del Partido a finales de los años cincuenta. Con el alejamiento respecto del núcleo comunista, que había intensificado su aislamiento político y social del resto de grupos del exilio español (Carrión, 2004), se constata un incremento de las relaciones con los exiliados relacionados con la Institución Libre de Enseñanza, más concretamente con la entidad que los agrupaba, la Corporación de Antiguos Alumnos de la Institución Libre de Enseñanza del InstitutoEscuela y de la Residencia de Estudiantes de Madrid, grupo de México. La distancia que había generado la Guerra Civil se fue acortando y la pareja asistió a varias reuniones del grupo; Ballesteros incluso colaboró en el $\mathrm{Bo}$ letín de la Corporación (García-Velasco et al., 2017; Ballesteros, 1963).

Como se ha mostrado a lo largo de estas páginas, Antonio Ballesteros Usano tuvo una larga vida que abarcó diversas facetas, cada una más intensa que la anterior. Su universo ideológico estuvo presidido por profundas inquietudes sociales y durante décadas, en pleno periodo estalinista, fue un disciplinado militante comunista, aunque en los últimos años de su vida esos vínculos se atemperaron. Junto a la innegable importancia de la cultura comunista en su orientación política, también se constata la sólida presencia de la cultura pedagógica del movimiento de la Escuela Nueva y de la Institución Libre de Enseñanza que perduró desde su etapa de formación hasta el final de su actividad profesional.

La presencia de diversas identidades en la trayectoria de un personaje, en este caso
Antonio Ballesteros, con su secuela de coincidencias, acercamientos y alejamientos, es un aspecto sumamente interesante, aunque escasamente tratado. Hasta donde hemos podido documentar fehacientemente, las cuestiones relacionadas con su militancia política no ofrecen ninguna duda. Igualmente, ha quedado plenamente constatado por medio de elementos tan relevantes como su destacada trayectoria editorial, los testimonios de sus antiguos alumnos y el reconocimiento de los responsables de las instituciones en las que trabajó, que su ideario educativo estuvo básicamente centrado en los planteamientos del movimiento de la Escuela Nueva, con una notable presencia del modelo netamente liberal y reformista de la Institución Libre de Enseñanza. En estos programas se identifica un notable interés por las cuestiones más sociales, pero dentro de los parámetros innovadores característicos de ese movimiento.

En un curioso equilibrio, en la esfera política de Antonio Ballesteros puede dibujarse un panorama en el cual prevaleció por mucho tiempo la cultura comunista frente a la liberal. Ahora bien, en lo que respecta al ámbito pedagógico, la cultura innovadora de la Escuela Nueva y, dentro de ella, el modelo educativo liberal de la ILE, resulta claramente predominante. Antonio Ballesteros defendió y promovió la escuela pública y estuvo profundamente interesado en la democratización de la enseñanza, pero no se le puede atribuir en ningún momento el rol de divulgador de la pedagogía comunista. Sus textos, tanto los editados en España como los publicados en México o en Argentina, se centran en los aspectos típicos de la Escuela Nueva: la renovación organizativa de la escuela, el paidocentrismo, la dimensión social de la educación, etc. No defendió en sus trabajos los métodos de la pedagogía soviética ni divulgó sus métodos organizativos y didácticos.

Antonio Ballesteros fue un competente profesional de la enseñanza, ya fuera como inspector en España, formador de maestros y 
maestras de enseñanza primaria y especialistas en pedagogía en suelo mexicano o, en todo lugar y momento, como estudioso y divulgador de la innovación pedagógica. Asimismo, fue un hombre de su tiempo, comprometido políticamente con los avanzados planteamientos pedagógicos de la II República Espanola que, pese a la derrota y el exilio, se mantuvo fiel a sus ideas. Esa intensa vida entre dos continentes y con la educación como bandera se extinguió el 21 de abril de 1976 en la Ciudad de México a consecuencia de las secuelas de un accidente. En octubre, pocos meses después, falleció su esposa, Emilia Elías.

\section{RECONOCIMIENTO Y MEMORIA}

Para finalizar queremos dedicar unos últimos párrafos al reconocimiento que ha recibido la trayectoria de Antonio Ballesteros Usano con el fin de subrayar el contraste de algunos hechos. Tanto él como Emilia Elías fueron especialmente apreciados por alumnos y compañeros de claustro que reconocieron sus amplios conocimientos y la seriedad en el desempeño profesional (Escuela Nacional de Maestros, 1975; Becerra, 1994; Pérez, 1997; Farfán, 2004). A mediados de la década de 1960 fueron objeto de un homenaje organizado por antiguos alumnos, con ocasión del 25 aniversario de sus trabajos en la Escuela Nacional de Maestros.

Con motivo de su jubilación en 1968 también recibieron reiteradas muestras de agradecimiento. El director de la Escuela les dirigió una carta a ambos en la cual, entre otras apreciaciones, los calificaba de "dos pilares de la educación mexicana, dos grandes amigos de México y leales amigos personales que nunca podremos sustituir". ${ }^{13}$ Igualmente, cuando el maestro Ballesteros tuvo que abandonar la UNAM, Francisco Larroyo, director de la Facultad de Filosofía y Letras, le rindió "un vivo testimonio de reconocimiento por los inestimables y eminentes servicios prestados" (Becerra, 1994: 291). Además, aún en vida, el maestro Ballesteros recibió con gran satisfacción que una escuela ubicada en la zona de Tlatelolco de la Ciudad de México fuera rotulada con su nombre: la escuela secundaria diurna No. 106 "Antonio Ballesteros Usano".

Más recientemente, su figura ha sido recordada en diversas iniciativas y su memoria continúa presente en algunos círculos de maestros y maestras (Reyes, 1982; Monter, 2011). Buena prueba de ello fueron el homenaje y la exposición que se realizaron en la Escuela Nacional de Maestros en 2009, dentro de los actos para conmemorar las aportaciones de los profesores españoles a dicha institución. Igualmente, sus antiguos alumnos de la Normal de Pachuca organizaron en 2015 un sentido acto en recuerdo de los maestros exiliados españoles que llegaron a sus aulas huyendo del régimen franquista. ${ }^{14}$

Dentro de este apartado de reconocimiento debemos mencionar la sorprendente continuidad de los textos que publicó, algunos de los cuales han tenido reediciones años después de su fallecimiento. Esto indica la potente influencia de esos libros, esparcidos por las bibliotecas normalistas de toda la República, para consulta de las nuevas generaciones de alumnos y que aún son citados hoy en día en trabajos finales.

Nada parecido ha sucedido en España. La figura de Antonio Ballesteros Usano, uno de los profesionales de la enseñanza más fervientes defensores de la escuela pública de su país, con la palabra y con los hechos, no cuenta con ninguna presencia pública y, que sepamos, ningún centro docente lleva su nombre. Sólo investigadores y especialistas conocen algunas de sus muchas aportaciones a la educación española y mexicana, mientras continúa siendo un perfecto desconocido para la inmensa mayoría de la población de su España natal.

\footnotetext{
13 AFBE; Carta del director de la Escuela Nacional de Maestros con fecha 17 de febrero de 1968.

14 Ver: https://www.facebook.com/gruponormalistahidalgo/posts/estimadas-exalumnas-yo-exalumnos-de-la-escuela-normal-urbana-federalizada-hoy-ce/1045734055459587/ (consulta: 24 de junio de 2020).
} 
Archivo General de la Administración (AGA), Archivo del Ministerio de Educación y Ciencia, caja 1816-23, Alcalá de Henares (España).
Archivo de la Familia Ballesteros-Elías (AFBE), Ciudad de México.

\section{REFERENCIAS}

AndrÉs, T., A. Ballesteros Usano, A. Bernárdez, E. G[ómez] Nadal, E. Naval, T. Navarro Tomás, T. Pérez Rubio, J.M. Ots, A. Rodríguez Monino, L. Santullano y M. Zambrano (1937), Labor cultural de la República Española durante la guerra, Valencia, Gráficas Vives.

Aznar, Manuel (2019), "Prólogo. El tamaño de la memoria”, en Joaquín Recio (ed.), Caja 128. Poesíal/ Polítical/ Rejano. Texto y memoria de Juan Rejano, Sevilla, Archivo Histórico del PCE, Diputación de Córdoba, pp. 15-43.

Ballesteros Márquez, Francisco (1888), La escuela primaria y la educación del proletariado. Discurso leído por don Francisco Ballesteros y Márquez en el Ateneo científico-literario de Córdoba, la noche del 17 de abril de 1888, Córdoba, Imprenta, librería y litografía del Diario.

Ballesteros Márquez, Francisco (1899), Pedagogía. Educación y didáctica pedagógica y práctica de la enseñanza, Córdoba, La Región Andaluza.

Ballesteros Márquez, Francisco (1906), Pedagogía. Práctica de la educación y de la enseñanza a Málaga, Málaga, Tipografía La Equitativa.

Ballesteros Usano, Antonio (1924), Distribución del tiempo y del trabajo, Madrid, Revista de Pedagogía.

Ballesteros Usano, Antonio (1926), La escuela graduada, Madrid, Revista de Pedagogía.

Ballesteros Usano, Antonio (1928a), El método Decroly, Madrid, Revista de Pedagogía.

Ballesteros Usano, Antonio (1928b), La cooperación en la escuela, Madrid, Revista de Pedagogía.

Ballesteros Usano, Antonio (1930), Las escuelas nuevas francesas y belgas, Madrid, Revista de Pedagogía.

Ballesteros Usano, Antonio (1935), La preparación del trabajo en la escuela, Madrid, Revista de Pedagogía.

Ballesteros Usano, Antonio (1937), “Instrucción primaria”, en T. Andrés, A. Ballesteros Usano, A. Bernárdez, E. G[ómez] Nadal, E. Naval, T. Navarro Tomás, T. Pérez Rubio, J.M. Ots, A. Rodríguez Monino, L. Santullano y M. Zambrano, Labor cultural de la República Española durante la guerra, Valencia, Gráficas Vives, pp. 581-586.
Ballesteros Usano, Antonio (1939, 12 de junio), "La escuela popular mexicana”, Sinaia. Diario de la Primera Expedición de Republicanos. España México, núm. 18, pp. 12 y 20.

Ballesteros Usano, Antonio (1940), Cómo se organiza la cooperación en la escuela primaria, México, Edipasa.

Ballesteros Usano, Antonio (1943), Organización de la escuela primaria, México, Patria.

Ballesteros Usano, Antonio (1953), "La nueva ley franquista de enseñanza media. Causas profundas de una reforma educativa", Nuestro Tiempo, núm. 9, pp. 64-67.

Ballesteros Usano, Antonio (1963), "Don Francisco en la biblioteca", Boletín de la Corporación, núm. 57, s/p.

Ballesteros Usano, Antonio (1965), La adolescencia: ensayo de una caracterización de esta edad, México, Patria.

Ballesteros Usano, Antonio y Fernando Sáinz (1934), Organización escolar, Madrid, Revista de Pedagogía.

Ballesteros Usano, Antonio y Fernando Sáinz (1952), Organización escolar, Buenos Aires, Losada.

BArreiro, Herminio (1984), Lorenzo Luzuriaga y la escuela pública en España (1889-1936), Ciudad Real, Diputación Provincial.

BARreiro, Herminio (1989), Lorenzo Luzuriaga y la renovación educativa en España (1889-1936), A Coruña, Ediciós do Castro.

Becerra, José Luis (1994), “Antonio Ballesteros”, Setenta años de la Facultad de Filosofía y Letras, México, UNAM, pp. 289-291.

Canales, Antonio Fernando (2019), "El CSIC en el sistema de I+D español desde su creación al tardo-franquismo", en Lorenzo Delgado y Santiago M. López, (eds.), Ciencia en transición. El lastre franquista ante el reto de la modernización, Madrid, Silex, pp. 39-62.

Cantón, Valentina (1995), Educación y Cultura. Revista de los Maestros Españoles en el Exilio (1940), México, Universidad Pedagógica Nacional.

Cantón, Valentina (1999), "El exilio español y la escuela popular mexicana. Un apunte del maestro Antonio Ballesteros Usano", Correo del Maestro, núm. 37, pp. 21-37. 
Carrión, Pablo Jesús (2004), “La delegación del PCE en México (1939-1956). Origen y límite de una voluntad de liderazgo de la oposición", Espacio, Tiempo y Forma, núm. 16, pp. 309-336.

CAstán, José Luis (2017), “La organización de la inspección de educación en la II República Española: el decreto de 2 de diciembre de 1932", Supervisión 21, núm. 46, pp. 1-41, en: http:// usie.es/supervision-21/ (consulta: 7 de enero de 2020).

Civera, Alicia (2011), "Exile as a Means for the Meeting and Construction of Pedagogies: The exiled Spanish Republican teachers in Mexico in 1939", Paedagogica Historica, vol. 47, núm. 5, pp. 657-677.

Civera Alicia y José Ignacio Cruz (2017), "Introducción en Emilia Elías de Ballesteros”, en José Ignacio Cruz y Alicia Civera (eds.), Problemas educativos actuales, Madrid, Biblioteca Nueva, pp. 1-40.

"Colofón" (1939, 12 de junio), Sinaia. Diario de la Primera Expedición de Republicanos. España México, núm. 18, p. 21 (edición facsímil 1989), México, UAM/UNAM/La oca/Redacta.

Cruz, José Ignacio (2005), Los colegios del exilio en México, Madrid, Residencia de Estudiantes.

Cruz, José Ignacio (2011), "El exilio pedagógico de 1939. Datos, reflexiones e interpretaciones", en Margarita Lourendo y Antón Costa (eds.), Exílios e viagens. Idearios de liberdade e discursos educativos. Portugal-Espanha séc. XVIII-XX, Porto, Sociedade Portuguesa de Ciências da Educação/CIIE-FPCE-UP/Sociedad Española de Historia de la Educación, pp. 137-156.

Cruz, José Ignacio (2018), "València, capital de la infancia evacuada", en Javier Navarro y Sergio Valero (eds.), València capital de la República. 1936-1937. La ciutat de la saviesa, vol. 3, Valencia, Ayuntament de València, pp. 57-80.

De LuIs, Francisco (2002), La FETE en la Guerra Civil Española (1936-1939), Barcelona, Ariel.

De Luis, Francisco (2009), La FETE (1939-1982): de la represión franquista a la transición democrática, Madrid, Tecnos.

Del Pozo, María del Mar (2003-2004), "La Escuela Nueva en España: crónica y semblanza de un mito", Historia de la Educación, núm. 22-23, pp. 317-346.

Dubet, François (1989), "De la sociología de la identidad a la sociología del sujeto", Revista Estudios Sociológicos, vol. 7, núm. 21, pp. 519-545.

ElíAs, Emilia y Antonio Ballesteros Usano (1955), Civismo para primer año de secundaria, México, Patria.

Elías, Emilia y Antonio Ballesteros Usano (1969), La educación de los adolescentes, México, Patria.
Escuela Nacional de Maestros (1975), Presencia de tres actos normalistas. Práctica foránea, representación teatral y exposición funcional, México, Escuela Nacional de Maestros.

FARfán, Jesús (2004), "Un profesor en el exilio: Antonio Ballesteros Usano", Educación 2001. Revista Mexicana de Educación, núm. 114, pp. 75-78.

GARcía-Velasco, José, James Valender, Tatiana Aguilar-Álvarez Bay y Trilce Arroyo (eds.) (2017), Alberto Jiménez Fraud. Epistolario, 1905-1964, 3 vols., Madrid, Fundación Unicaja/Publicaciones de la Residencia de Estudiantes.

JiménEZ, Juan Alfredo (1984), La inspección de primera enseñanza en la segunda república española, Salamanca, Universidad de Salamanca.

Julia, Dominique (1995), "La culture scolaire comme objet historique”, en Antonio Nóvoa, Mar Depaepe y Erwin W. Johanningmeier (eds.), Colonial Experience in Education. Historical Issues and Perspectives, Gante, Paedagogica Historica, Supplementary, pp. 353-382.

López, María Teresa (2013), Historia de la inspección de primera enseñanza en España, Madrid, Ministerio de Educación, Ciencia y Deporte.

"Los peques" (1939, 11 de junio), Sinaia. Diario de la primera expedición de republicanos. España México, núm. 17, edición facsímil 1989, México, UAM/UNAM/La oca/ Redacta, p. 1.

Luzuriaga, Lorenzo, Antonio Ballesteros Usano y Fernando Sáinz (1961), Métodos de la educación nueva, Buenos Aires, Losada.

Marín, Teresa (1991), Innovadores de la educación en España. (Becarios de la Junta para la Ampliación de Estudios), Cuenca, Universidad de Castilla-La Mancha.

Molero, Antonio y María del Mar Pozo (1989), Escuela de Estudios Superiores del Magisterio (1909-1932). Un precedente histórico en la formación universitaria del profesorado español, Madrid, Universidad de Alcalá de Henares.

Monter, Ricardo (2011), "Antonio Ballesteros Usano y su presencia en la Escuela Nacional de Maestros", en: http://www.comie.org.mx/congreso/ memoriaelectronica/v11/docs/area_09/1377. pdf (consulta: 12 de octubre de 2019).

Montero, Ana María (2008), "Ballesteros Márquez, Francisco", en María Isabel Corts y María Consolación Carderón (coords.), Estudios de historia de la educación andaluza: textos $y$ documentos (siglos XVIII, XIX y XX), Sevilla, Universidad de Sevilla, pp. 69-74.

Moreno, Javier, Fernando Martínez, José García-Velasco, Antonio Morales, Gonzalo Capellán y Eugenio Otero (2013), La Institución Libre de Enseñanza y Giner de los Ríos: nuevas perspectivas, Madrid, Acción Cultural Española/ Fundación Francisco Giner de los Ríos. 
Oropeza, Luciano y María Guadalupe García (2019), "Aportaciones al debate del estudio de las identidades y las biografías", Diálogos sobre Educación, vol. 10, núm. 18, pp. 1-14, en: http:// www.scielo.org. $\mathrm{mx} / \mathrm{scielo}$.php? script $=\mathrm{sci}$ arttext\&pid=S2007-21712019000100009\&lng= es\&nrm=iso\&tlng=es (consulta: 31 de agosto de 2020).

PÉREZ, Luis (1997), La relación teoría-práctica en la formación de maestros de primaria, Tesis de Maestría, Pachuca (México), Universidad Autónoma del Estado de Hidalgo.

PÉrez, Manuel (2006), "La Guerra Civil y la historiografía: no fue posible el acuerdo", Ler História, núm. 5, pp. 51-75.

Pla, Dolores (2003), El aroma del recuerdo. Narraciones de españoles republicanos refugiados en México, México, Plaza y ValdésConaculta-INAH.

Reyes, Juan José (1982), “Escuela, maestros y pedagogos”, en (s/e), El exilio español en México 1939-1982, México, Salvat/Fondo de Cultura Económica, pp. 177-204.

Rutter, Michael (1996), “Transitions and Turning Points in Developmental Psychopathology: As applied to the age span between childhood and mid-adulthood", International Journal of Behavioral Development, vol. 19, núm. 3, pp. 603-626.

SÁnCHez Ron, José María (coord.) (1988), 1907-1987. La Junta para Ampliación de Estudios e Investigaciones Científicas 80 años después, 2 vols., Madrid, CSIC.
VAlender, James (2017), “Alberto Jiménez Fraud en el exilio", en José García-Velasco, James Valender, Tatiana Aguilar-Álvarez Bay y Trilce Arroyo (eds.), Alberto Jiménez Fraud. Epistolario II, 1905-1964, Madrid, Fundación Unicaja/Publicaciones de la Residencia de Estudiantes, pp. III-XXXI.

Valles, José Manuel, José Luis Mora, Carlos Dueñas, Juan Luis García y Juan Manuel Moreno (2019), La Universidad Popular Segoviana. Antecedentes, historia y protagonistas, 3 vols., Segovia, Real Academia de Historia y Arte de San Quirce.

VIÑAO, Antonio (1994-1995), "La modernización pedagógica española a través de la Revista de Pedagogía (1922-1936)", Anales de Pedagogía, núm. 12-13, pp. 7-45.

VIÑAO, Antonio (2000), Sistemas educativos, culturas escolares y reformas. Continuidades y cambios, Madrid, Morata.

VIÑAO, Antonio (2003), "La renovación de la organización escolar. La escuela graduada”, en Gabriela Ossenbach (coord.), Psicología y pedagogía en la primera mitad del siglo XX, Madrid, UNED, pp. 73-104.

VIÑAO, Antonio (2008), "La escuela y la escolaridad como objetos históricos. Facetas y problemas de la historia de la educación”, en Juan Mainer (coord.), Pensar críticamente la educación escolar. Perspectivas y controversias historiográficas, Zaragoza, Prensas Universitarias de Zaragoza, pp. 83-118.

Zafra, Enrique, Rosalía Crego y Carmen Heredia (1989), Los niños españoles evacuados a la URSS (1937), Madrid, Ediciones La Torre. 